\title{
Estrutura de capital dos bancos: Discussões teóricas acerca de sua relevância na maximização de valor
}

\author{
Bank Capital Structure: Theoretical Discussions About Its Relevance in Value \\ Maximination
}

\author{
Alexandre Franco de Godoi ${ }^{I}$ \\ José Odálio dos Santos ${ }^{\text {II }}$ \\ Fernando de Almeida Santos ${ }^{\text {III }}$ \\ José Carlos Marion ${ }^{\mathrm{IV}}$
}

\begin{abstract}
Resumo
A captação de recursos pelos bancos pode afetar significativamente seus resultados. Há uma clara preferência pelo capital de terceiros na estrutura de capital (depósitos de clientes) como forma de captação menos onerosa para alavancagem de resultados. Determinadas particularidades da indústria financeira como os requerimentos de capital regulatório, as garantias e proteções governamentais e privadas e as imperfeições existentes nos mercados, são alguns aspectos que sinalizam para a relevância da estrutura de capital nos bancos. Como um tema controverso, a estrutura de capital desperta crescente interesse acadêmico por pesquisas críticas que tratem de sua relevância para a maximização de valor, motivando o desenvolvimento deste ensaio que contribui no campo teórico e decisório ao oportunizar o debate crítico sobre o tema.
\end{abstract}

Palavras-chave: Relevância da Estrutura de Capital; Alavancagem Financeira; Estrutura de Capital dos Bancos.

\begin{abstract}
Fundraising by banks can significantly affect their bottom line. There is a clear preference for debt in the capital structure (customer deposits) as a less costly form to raise results. Certain particularities of the financial industry, such as capital regulatory requirements, government, and personal guarantees and protections, and market imperfections, are some aspects that indicate the capital structure relevance in banks. As a controversial issue, the capital structure arouses growing academic interest in critical research that deals with its relevance to value maximization, motivating the development of this essay that contributes to the theoretical and decisive field by providing the critical debate on the subject.
\end{abstract}

Keywords: Capital Structure Relevance; Financial Leverage; Bank Capital Structure.

I E-mail godoi_franco@hotmail.com Pontifícia Universidade Católica de São Paulo/PUC-SP, São Paulo/SP [Brasil] -

(D) ORCID Id: http://orcid.org/0000-0002-4879-8520

II E-mail j.odalio@pucsp.br, Pontifícia Universidade Católica de São Paulo/PUC-SP, São Paulo/SP [Brasil] - (D) ORCID Id: https://orcid.org/0000-0001-6428-723X

III E-mail almeidasantos@pucsp.b, Pontifícia Universidade Católica de São Paulo/PUC-SP, São Paulo/SP [Brasil] (D) ORCID Id: https://orcid.org/0000-0002-1716-2802

IV E-mail jcmarion@usp.br, Pontifícia Universidade Católica de São Paulo/PUC-SP, São Paulo/SP [Brasil] - (D) ORCID Id: https://orcid.org/0000-0002-5641-6107 


\section{Introdução}

A Teoria de Finanças Corporativas compreende estudos que confirmam a relevância da estrutura de capital para a criação de valor, embora ainda persistam certas divergências quanto à determinação de uma estrutura ótima de capital. Quando o principal aspecto nos debates sobre a estrutura de capital trata-se da criação de valor para empresas e acionistas, duas correntes teóricas são predominantes (Machado et al., 20I5), sendo a Teoria Tradicionalista que aborda a relevância da estrutura de capital para a geração de valor (Durand, I952, I959) e a Teoria da Irrelevância da Estrutura de Capital que considera o modo como as empresas se financiam irrelevante para a criação de valor (Modigliani \& Miller, I958).

As divergências entre essas duas correntes teóricas levaram ao surgimento de outras teorias que tratam a estrutura de capital como questão central. Embora possam existir diferentes posições quanto à existência de uma estrutura ótima de capital, não há ainda um consenso definitivo entre os pesquisadores a respeito de sua relevância ou irrelevância para a maximização de valor, tampouco a predominância de uma teoria universal e perfeita que seja capaz de explicar por completo o comportamento das empresas em relação à estrutura de capital. Em razão disso, esse tema trata-se de um dos mais controversos dentro das finanças corporativas, continuando a demandar, até os dias atuais, a realização de pesquisas que analisem a aplicação das teorias desenvolvidas e os diversos inter-relacionamentos com outros aspectos corporativos (Nisiyama \& Nakamura, 20I5).

Majoritariamente, as pesquisas empíricas desenvolvidas sobre a estrutura de capital têm sido realizadas em empresas não financeiras, excluindo-se das análises aquelas empresas que pertencem ao setor financeiro, especialmente os bancos, sob justificativas de particularidades inerentes ao tipo de atividade desenvolvida, os riscos a que estão expostas essas empresas, os elevados níveis de alavancagem financeira característicos desse negócio e a atividade regulatória fortemente presente no setor.

Os bancos apresentam características específicas que os diferenciam das empresas não financeiras, notadamente quanto à atuação dentro do mercado de capitais como intermediários financeiros entre investidores e tomadores de recursos, viabilizando o fluxo de crédito na economia (Diamond \& Rajan, 200I) e 
desempenhando papel preponderante para o funcionamento do sistema econômico e desenvolvimento dos países (Belém \& Gartner, 20I6). A administração da estrutura de capital nessas empresas envolve decisões que devem ser tomadas de maneira eficiente quando da captação de depósitos e administração das necessidades de reservas (Saunders, 2000). Afinal, a forma como os bancos realizam a captação de recursos pode afetar significativamente seus resultados.

A elevada dependência de recursos de terceiros na estrutura de capital, sobretudo maiores níveis de depósitos de clientes, proporcionam maior volume de recursos disponíveis para a intermediação financeira (Mendonça et al., 20I6), e como uma das formas de captação menos onerosa, por ser obtida a taxas de juros reduzidas, geralmente abaixo da taxa livre de risco da economia, ou até mesmo isento de ônus como ocorre com os depósitos à vista (Vieira, 20I6), possibilitam aos bancos uma alta capacidade de alavancagem dos resultados (Assaf Neto, 2OI5).

Uma particularidade inerente a esse tipo de recurso trata-se dos instrumentos de segurança colocados à disposição dos bancos sob a forma de garantias oferecidas por órgãos privados ou governamentais, seguros de depósitos e outras garantias implícitas de resgate (Jucá, 2OII), os quais contribuem para a redução dos riscos e dos custos de captação perante os depositantes (Vieira, 2OI6). Além disso, algumas imperfeições existentes nos mercados parecem distanciar as circunstâncias reais do ambiente em que atuam os bancos da abordagem da irrelevância da estrutura de capital (Octavia \& Brown, 2008).

Pelo exposto, poder-se-ia admitir, ainda que de modo intuitivo inicialmente, a relevância da estrutura de capital para os bancos (Aboura \& Lépinette, 20I5). No entanto, como os bancos convivem com diversas restrições e controles legais em seus passivos, ainda persistem discussões quanto à capacidade dessas empresas criarem valor a partir de seus passivos (Assaf Neto, 20I5). Assim, a atualidade, relevância e debates críticos inevitáveis sobre a relevância da estrutura de capital para os bancos que são mantidos por agentes tomadores de decisões, órgãos reguladores e a própria comunidade acadêmica, motivam o surgimento do seguinte problema de pesquisa: A estrutura de capital pode ser considerada relevante para os bancos? 
Por meio de um ensaio teórico, a pesquisa tem por objetivo dissertar sobre os principais argumentos que possibilitem sustentar a relevância da estrutura de capital para os bancos. O ensaio trata-se de um artigo conceitual que permite uma exposição de forma lógica e coerente em sua argumentação (Martelanc, 20IO). Como uma importante forma de geração de conhecimento, o ensaio é utilizado por várias áreas, especialmente nas ciências sociais, e sua característica mais elementar é a originalidade que pode estar na argumentação, na escolha do objeto de análise ou no recorte dado a um determinado tema (Meneghetti, 20II). O campo administrativo tem na metodologia do ensaio um importante instrumento de análise, levando-se em conta que o campo de estudos científicos em administração trata-se de terreno fértil para pesquisas empíricas e teórico-empíricas (Boava, Macedo \& Sette, 20I2).

Como contribuição no campo teórico, o presente ensaio possibilita oportunizar o debate acadêmico inevitável acerca da relevância da estrutura de capital para os bancos. No campo social, espera-se que possa contribuir para o processo decisório de gestores, investidores, analistas financeiros e órgãos reguladores do setor. A justificativa para o desenvolvimento da pesquisa está baseada no crescente interesse da área acadêmica em pesquisas direcionadas para análise crítica da estrutura de capital de empresas financeiras.

Quanto às suas limitações, elas se referem à própria estratégia de pesquisa utilizada para o tema, pois foi privilegiada a exposição de argumentos que sustentem a relevância da estrutura de capital para os bancos. Logo, não é objetivo do presente ensaio discutir aspectos que estejam relacionados à irrelevância da estrutura de capital e aos fatores que possam ser considerados determinantes para a estrutura de capital dessas empresas, emergindo assim essas questões como recomendações para o desenvolvimento de reflexões futuras.

\section{Particularidades da Atividade dos Bancos e de sua Estrutura de Capital}

Os bancos apresentam características exclusivas que os diferenciam das empresas não financeiras. Como entidades públicas ou privadas, com finalidades lucrativas, os bancos como depositários da poupança de famílias, empresas e 
investidores institucionais, atuam como intermediários financeiros entre investidores e tomadores de recursos (Pinheiro, Savóia \& Securato, 20I5), desempenhando papel determinante para o funcionamento dos sistemas econômicos e desenvolvimento dos países (Belém \& Gartner, 20I6).

Ao promover a realização de operações de empréstimos de recursos advindos, em grande parte, de seus depositantes, os bancos viabilizam o fluxo de oferta de crédito na economia (Diamond \& Rajan, 200I) e determinam a criação do poder de compra necessário para empresas e pessoas físicas (Maffili, Bressan \& Souza, 2007). Em outras palavras, atuam de forma decisiva sobre as condições de financiamento da economia e sobre o nível de gastos dos agentes (Paula, I999), sendo provedores de liquidez e segurança ao sistema financeiro e indutores do desenvolvimento pela concessão de crédito para consumo e investimentos (Andrade, 20I4).

A alta complexidade e diversidade da atividade bancária expõem os bancos a vários tipos de riscos de intermediação financeira que podem fragilizar a sua situação econômico-financeira (Belém \& Gartner, 2OI6). Do mesmo modo que as empresas não financeiras, os bancos fazem uso do capital de terceiros e do capital próprio como fontes importantes de recursos para a sua estrutura de capital que, respeitadas as restrições regulatórias existentes, podem ser utilizadas para o financiamento de novos projetos e para a expansão das operações (Saunders, 2000).

Há um elevado nível de endividamento na composição da estrutura de capital bancária, dada a preferência dos bancos em operar com recursos do capital de terceiros (aplicadores e depositantes), tornando assim bastante reduzida a participação do capital próprio (capital e reservas), em média ı\% do capital emprestado em atendimento aos requerimentos regulatórios de capital previstos nos Acordos de Basileia (Assaf Neto, 2015). O capital próprio mantido na estrutura de capital é fortemente dependente dos riscos assumidos nos negócios (Assis, 20I7), sendo utilizado para definir os limites de empréstimos e demais operações ativas, mitigar a exposição aos riscos e cobrir eventuais perdas (Assaf Neto, 20I5).

Ao adotar estratégias para o aproveitamento de eventuais oportunidades de lucros em suas operações ativas, os bancos tornam-se atuantes na captação de depósitos e na administração das necessidades de reservas (Maffili, Bressan \& Souza, 
20O7), seja pelo gerenciamento ativo dos recursos captados ao criar incentivos para atrair novos depositantes e selecionar os melhores depósitos (Paula, Alves Júnior \& Marques, 20OI), seja pela definição de políticas adequadas para suas necessidades de reservas (Kakinami, 2007).

Logo, a forma como os bancos captam recursos para financiar seu capital pode afetar consideravelmente seus resultados. Maiores níveis de depósitos de clientes compondo sua estrutura de capital geram maior volume de recursos disponíveis para a intermediação financeira (Mendonça et al., 20I6) e representam uma forma de captação menos onerosa para incremento da lucratividade bancária, tendo em vista as garantias por meio de seguros de depósitos oferecidas por órgão privado ou órgão governamental que contribuem para redução de riscos e de custos de captação perante os depositantes (Vieira, 20I6).

O uso do endividamento na estrutura de capital proporciona ainda um benefício fiscal para os bancos, em razão da dedutibilidade dos juros incorridos sobre o lucro tributável e um melhor monitoramento por terceiros da própria atividade bancária, servindo como instrumento de disciplina que possibilita mitigar o conflito de interesses existente entre acionistas e administradores (Vieira, 2OI6).

Por outro lado, maiores níveis de endividamento na estrutura de capital podem representar baixa capitalização para os bancos e levar ao aumento de propensão ao risco e de custos (Gonçalves et al., 20I2), especialmente em relação aos riscos associados à falência e aos custos de agência da dívida que se originam do conflito de interesses entre credores e acionistas (Vieira, 20I6). Dependendo da situação financeira dos bancos, os depositantes podem exigir juros mais elevados sobre seus depósitos, elevando os custos associados à captação de recursos e, consequentemente, impactando de forma negativa na rentabilidade bancária (Vieira, 20I6).

Intuitivamente, poder-se-ia admitir a relevância da estrutura de capital para os bancos, não apenas por razões atreladas a aspectos regulatórios como um dos atritos que distancia a realidade do mercado da proposição de irrelevância da estrutura de capital (Octavia \& Brown, 2008), mas também em razão da elevada dependência de recursos de terceiros que, ao mesmo tempo em que possibilita grande capacidade de alavancagem dos resultados (Assaf Neto, 2015), expõem os bancos a riscos e custos 
pelo uso de dívidas (Vieira, 2OI6). A estrutura de capital nessas empresas sofre ainda a influência de condições particulares da indústria financeira, como a regulação governamental e o uso de instrumentos de segurança - os seguros de depósitos e o banco central atuando como um credor dos bancos (Kwan, 2009).

\section{O Papel do Capital para os Bancos}

O capital representa para os bancos uma base de fundos permanentemente empregados nos negócios para garantir a estabilidade financeira e os recursos necessários para lidar com possíveis adversidades (Mantovani \& Santos, 2015). Do ponto de vista da regulação bancária, a gestão do capital e a definição de capital adequado são medidas fundamentais para sustentação da economia (Andrade, 2014). O argumento favorável à regulação dos bancos está relacionado ao fato de eventuais perturbações ou interferências importantes nas funções desempenhadas e nos serviços prestados, produzirem efeitos prejudiciais na economia (Saunders, 2000).

Logo, para garantir um ambiente seguro e de solidez para o sistema financeiro, evitando-se assim que perdas inesperadas ou problemas financeiros a que estejam submetidos os bancos possam comprometer como um todo o sistema de intermediação financeira (Vallascas \& Hagedorff, 2OI3) e produzir efeitos prejudiciais para a economia dos países como mostram as crises sistêmicas (Saunders, 200o), órgãos reguladores do setor exigem dos bancos a manutenção de capital mínimo regulatório em níveis suficientes para suportar os vários tipos de riscos a que estão expostos e que podem fragilizar a sua situação financeira (Belém \& Gartner, 20I6).

As ações adotadas pelos bancos centrais nesse sentido necessitam ser coordenadas por instituição multilateral com isenção e representatividade para operar nesse ambiente (Pinheiro, Savóia \& Securato, 20I5). Os organismos financeiros internacionais com essa atribuição são o Bank for International Settlements (BIS), cujo objetivo é fomentar a cooperação entre os bancos centrais em busca da estabilidade monetária e financeira, e o Basel Committee on Banking Supervision (BCBS), encarregado de reforçar a regulação, supervisão e melhores práticas no mercado financeiro (Banco Central do Brasil [BACEN], 20I9a). Está sob responsabilidade do BCBS recomendar aos bancos centrais medidas de cunho prudencial para fortalecer a 
segurança de práticas financeiras e garantir a estabilidade financeira internacional. São os denominados Acordos de Basileia, cujo objetivo é limitar a alavancagem financeira dos bancos a níveis que proporcionem solidez para a economia dos países (BIS, I988).

O Acordo de Basileia I teve como foco da regulação o risco de crédito (risco de default de empréstimos), submetendo às exigências de capital regulatório apenas as operações de empréstimos (BIS, I988). Esse acordo disciplinou a quantidade mínima de capital regulatório que os bancos deveriam manter para assegurar a estabilidade do sistema financeiro internacional (Belém \& Gartner, 20I6).

Como parte do processo de aprimoramento da estrutura prudencial aplicável aos bancos, foi editado o Acordo de Basileia II que passou a considerar, além do risco de crédito, a inclusão do risco de mercado e risco operacional para um capital regulamentar mais sensível ao risco (BIS, 2006). Novas diretrizes foram emitidas sobre como os bancos deveriam mensurar a exposição aos riscos e gerenciar seu nível de capital (Belém \& Gartner, 20ı6).

Pelo fato dos Acordos de Basileia I e II terem se mostrado insuficientes para impedir a alavancagem excessiva dos bancos (BACEN, 20I9a), em resposta às vulnerabilidades apresentadas pelo setor bancário durante a crise financeira de 2008, foi emitido o Acordo de Basileia III que passou a exigir uma nova estrutura de capital que priorizasse o capital de melhor qualidade para ampliar a resiliência e solidez dos bancos (BIS, 2OIO; Pinheiro, Savóia \& Securato, 20I5). Seria uma estrutura de capital mais efetiva na absorção de choques econômicos ou financeiros e na transferência de todo ônus da recuperação dos bancos para seus investidores e proprietários, ao invés de recair sobre os governos e a sociedade (Goes, Sheng \& Schiozer, 20I6).

A não observância das exigências de capital regulatório previstas nos Acordos de Basileia submete os bancos a penalidades aplicáveis pelos órgãos reguladores do setor (Rime, 20OI), ocasionando custos, restrições no seu portfólio de ativos, necessidades de novas capitalizações (Peura \& Keppo, 2006) e, em casos mais extremos, o encerramento das operações (Elizalde \& Repullo, 2007). Portanto, em razão dos custos e riscos que podem recair sobre os bancos, faz-se necessário manter uma estrutura de capital compatível com as expectativas de mercado, com disponibilidade de capital suficiente para explorar as oportunidades futuras de 
investimentos e a demanda por operações de empréstimos (Berger, Herring \& Szegö, I995; Jokipii \& O Milne, 2008). Esses aspectos regulatórios mencionados asseguram, por si só, a relevância da estrutura de capital para os bancos.

\section{As Teorias da Estrutura de Capital}

As teorias da estrutura de capital propõem discussões acerca de sua relevância para a maximização de valor nas empresas e em relação aos diversos interrelacionamentos que apresenta com outros aspectos corporativos (Nisiyama \& Nakamura, 2OI5). Basicamente, duas correntes teóricas predominam quando o aspecto principal na análise da estrutura de capital trata-se de sua importância para a maximização de valor (Machado et al., 20I5): (i) a Teoria Tradicionalista; e (ii) Teoria da Irrelevância da Estrutura de Capital.

A Teoria Tradicionalista pressupõe a existência de uma estrutura ótima de capital (combinação ótima entre capital de terceiros e capital próprio) que, ao minimizar o custo de capital total, possibilitaria maximizar o valor para a empresa (Durand, 1952, 1959). Contrapondo essa abordagem, a Teoria da Irrelevância da Estrutura de Capital (Modigliani \& Miller, 1958) considera que as decisões em relação à estrutura de capital seriam irrelevantes para o valor da empresa, não admitindo, portanto, a existência de uma estrutura ótima de capital que possibilite minimizar o custo de capital total e assim promover a maximização de valor.

Desenvolvida sob premissas de condições de ambientes de mercados perfeitos, livres de impostos sobre os indivíduos, com as empresas situadas na mesma classe de risco e com ausências de fatores como fricção nos mercados de capitais, custos de falência, custos de agência, assimetria de informações e de crescimento nos fluxos de caixa (Famá, Barros \& Silveira, 200I), a Teoria da Irrelevância da Estrutura de Capital de Modigliani e Miller (1958) assume maior importância no campo teórico como referência para o estudo da estrutura de capital e não como resultados finais, pois as condições para que o valor da empresa não seja afetado pelas decisões de financiamentos são as ausências de custos e de imperfeições de mercado (Myers, 20OI).

Levando-se em conta que as empresas atuam em ambientes reais de mercados imperfeitos, as decisões de financiamentos parecem claramente importar, em razão da 
presença de aspectos como a existência de impostos, assimetria de informações, custos de agência (Myers, 20OI), entre outras imperfeições de mercado. Ao levar em conta a presença desses aspectos, as novas abordagens teóricas para a estrutura de capital passam então a flexibilizar os pressupostos restritivos da Irrelevância da Estrutura de Capital (Cağlayan \& Şak, 2OIO).

Logo, aspectos como a existência de impostos sobre a renda de pessoas jurídicas e o efeito do benefício fiscal pelo uso do endividamento (Modigliani \& Miller, I963); a inclusão de efeitos do imposto sobre a renda de pessoas físicas como fator que pode contrabalancear os benefícios fiscais obtidos com o uso de dívidas na estrutura de capital (Miller, I977); o conflito de interesses entre credores, acionistas e administradores e os custos de agência decorrentes (Jensen \& Meckling, r976); o efeito da sinalização das decisões de estrutura de capital para investidores e outros interessados quanto às expectativas futuras para a empresa (Ross, I977); e a assimetria de informações entre empresas e investidores (Myers \& Majluf, r984) são alguns pontos que passam a ser inseridos nos novos debates.

Duas grandes teorias têm predominado nos estudos sobre a estrutura de capital. A Static-Tradeoff Theory trata da existência de uma estrutura ótima de capital, obtida mediante um nível ótimo de endividamento que possibilita maximizar os benefícios fiscais e minimizar os riscos e os custos associados ao uso de dívidas (Myers, I977, 1984, 200I). Contrapondo a ideia de existência de uma estrutura ótima de capital, a Pecking Order Theory não prediz um nível-alvo ou ótimo de capital, mas sim uma hierarquia de preferências entre as fontes de financiamentos que as empresas seguem à medida que surgem oportunidades de investimentos, optando primeiro pelo uso de recursos internos, para somente então, fazer o uso de recursos externos (Myers, I984).

As divergências entre as abordagens da Static-Tradeoff Theory e da Pecking Order Theory quanto à existência de uma estrutura ótima de capital e a incapacidade dessas teorias em explicar as variações no valor de mercado das empresas e os efeitos produzidos sobre a estrutura de capital (Silva et al., 20I6), levaram ao surgimento da Equity Market Timing Theory. Essa teoria sugere não existir uma estrutura ótima de capital, pois as empresas optam por emitir ações ao identificar janelas de oportunidades 
de mercado por meio da relação market-to-book, sinalizando para menores custos de seleção adversa e de emissão do capital próprio (Baker \& Wurgler, 2002).

Embora a literatura sobre a estrutura de capital possa ser considerada ampla, ela ainda não apresentou uma base empírica sólida para distinguir as forças e fraquezas das principais teorias propostas (Frank \& Goyal, 2009), afinal nenhuma delas provou até o momento ser totalmente conclusiva (Flannery \& Rangan, 2006; Myers, 1984) ou capaz de capturar tudo o que influencia as decisões de estrutura de capital nas empresas (Brealey, Myers \& Allen, 20I3). As pesquisas que tratam da estrutura de capital estão dentre as mais relevantes na área de finanças corporativas (Correa, Basso \& Nakamura, 2OI3), por explorar um dos temas mais controversos que vem sendo objeto de debates ao longo de décadas, especialmente no que diz respeito a sua relevância para a maximização de valor e os diversos inter-relacionamentos que apresenta com outros aspectos corporativos (Nisiyama \& Nakamura, 2OI5).

O estudo da estrutura de capital pode ser considerado igualmente relevante para os bancos (Jucá, 2OII), sendo as teorias desenvolvidas dentro das Finanças Corporativas oportunas e plenamente aplicáveis para compreensão da estrutura de capital nessas empresas (Maffili, Bressan \& Souza, 2007).

\section{A Relevância da Estrutura de Capital para os Bancos}

As proposições de Modigliani e Miller (1958) acerca da Irrelevância da Estrutura de Capital, mantidas as restrições nela previstas, poderiam ser, em uma análise inicial, adequadamente aplicável aos bancos (Jucá, 20II; Maffili, Bressan \& Souza, 2007; Miller, 1995). No entanto, ainda que se admita ser a estrutura de capital irrelevante para os bancos numa economia de mercados perfeitos - esse um dos pressupostos da Teoria da Irrelevância da Estrutura de Capital (Modigliani \& Miller, I958) -, essa teoria restaria prejudicada, afinal nesse tipo de ambiente econômico os bancos não teriam papel algum a desempenhar na transferência de recursos entre os agentes econômicos, uma vez que esses administrariam seus próprios ativos financeiros (Saunders, 2OOO).

Como os bancos atuam em ambientes de mercados reais e imperfeitos, determinados aspectos presentes nesses ambientes podem interferir diretamente nas decisões sobre a estrutura de capital. Logo, fatores como o benefício fiscal pelo uso do 
endividamento (Orgler \& Taggart Jr, I983); os custos privados de falência/insolvência (Saunders, 2000; Jucá, 2OII); os problemas de relação de agência e a assimetria de informações (Prescott, 20OI); o nível ótimo de endividamento e os custos de emissão para o capital próprio (Wall \& Peterson, I998); as garantias e proteções oferecidas por governos e órgãos privados (Aboura \& Lépinette, 20I5); e os requerimentos de capital regulatório (Octavia \& Brown, 20o8), são alguns aspectos que parecem distanciar a realidade dos bancos da abordagem da Irrelevância da Estrutura de Capital.

Do mesmo modo que as empresas não financeiras, os bancos também se beneficiam da dedutibilidade para fins fiscais dos juros exigidos sobre o capital de terceiros utilizado na estrutura de capital (Orgler \& Taggart Jr, I983). Se por um lado o uso do capital de terceiros oferece a vantagem de benefícios fiscais, por outro maiores níveis de endividamento levam os bancos a incorrerem em custos privados de falência ou insolvência (Saunders, 200o). Quando há um aumento nos riscos das carteiras de ativos e nos níveis de alavancagem financeira, as decisões tomadas no âmbito dos bancos são no sentido de aumentar a proporção de capital próprio na estrutura de capital para limitar a probabilidade de falência (Kleff \& Weber, 2008).

Até mesmo nos bancos, a administração da estrutura de capital envolve decisões que precisam ser tomadas de maneira dinâmica na determinação de uma estrutura ótima de capital, obtida mediante um nível ótimo de endividamento que possibilite maximizar os benefícios fiscais e minimizar os riscos e os custos associados ao uso de dívidas, pressupostos esses que estão presentes na Static-Tradeoff Theory (Myers, 1977, 1984, 200I). As garantias e proteções oferecidas aos bancos pelos governos e órgãos privados sob a forma de instrumentos de segurança, reduzem qualquer benefício marginal proporcionado pelo uso do capital próprio na estrutura de capital (Brewer III, Kaufman \& Wall, 2008), limitando assim os níveis de riscos no setor bancário e os custos de dificuldades financeiras, criando então os estímulos necessários para que os bancos possam assumir maiores níveis de alavancagem financeira (Aboura \& Lépinette, 20I5).

O efeito da assimetria de informações entre insiders e outsiders é outro aspecto que também influencia as decisões de estrutura de capital nos bancos, pois ao tornar a captação de recursos por meio da emissão de capital próprio (ações) mais onerosa, a 
assimetria informacional cria condições propícias para o uso do endividamento na composição da estrutura de capital dessas empresas (Aboura \& Lépinette, 20I5).

Sob outra perspectiva, o uso do endividamento na estrutura de capital pode ajudar a disciplinar a atuação dos agentes, tornando-os mais cautelosos em relação às decisões arbitrárias e mais eficientes em suas funções (Aboura \& Lépinette, 2015). Como nos bancos há significativa geração de fluxo de caixa diariamente e várias oportunidades de investimentos (Souza, 2003), maiores níveis de endividamento na estrutura de capital podem servir como instrumento para mitigar o conflito de interesses entre agente e principal e restringir os custos de agência (Jensen, I986).

Embora o uso do endividamento possa mitigar os custos de agência que se originam do conflito de interesses entre administradores e acionistas, em contrapartida incentiva a formação de novo conflito que se dá entre acionistas e credores (Jucá, 2OII). Quando o endividamento se torna elevado, as expectativas quanto a uma possível quebra, intervenção ou liquidação aumentam o que faz com que os custos de agência do lado dos credores possam superar os custos dos acionistas e, como resultado, aumentar o custo total para os bancos (Berger \& Patti, 2005).

A efetiva supervisão existente no setor bancário e a regulação do capital determinam limites de alavancagem e estabelecem a exigência de depósitos compulsórios, influenciando a estrutura de capital dos bancos. Devido à maior exposição aos riscos que se originam com a elevada alavancagem financeira, órgãos reguladores do setor tornam obrigatório aos bancos o atendimento a determinados níveis de capital regulatório exigidos nos Acordos de Basileia para garantir um ambiente seguro e de solidez para o sistema financeiro (Belém \& Gartner, 20I6). Esses requerimentos de capital regulatório estabelecem exigências mínimas de capital próprio na estrutura de capital dos bancos que servem como colchão para a absorção de perdas inesperadas e de estresses financeiros, evitando assim que a quebra de determinado banco venha a contagiar outros mercados (Jucá, 2OII).

A decisão de se manter na estrutura de capital dos bancos um nível de capital próprio superior às exigências de capital regulatório previstos nos Acordos de Basileia pode ser explicada com base na Pecking Order Theory. De acordo com essa teoria, levando-se em conta as exigências de capital regulatório, a hierarquia de preferências 
nos bancos para composição da estrutura de capital levaria em conta, em primeiro lugar, a retenção de lucros gerados internamente como fonte de recursos próprios, para em seguida realizar a captação de depósitos, a emissão de outros tipos de dívidas e como último recurso, esgotada a sua capacidade de endividamento, a emissão de novas ações (Çăglayan \& Şak, 20IO; Kleff \& Weber, 2008; Romdhane, 2OIO).

Os Acordos de Basileia estão mais próximos de serem apontados como um dos atritos que distanciam as circunstâncias reais do ambiente em que operam os bancos da abordagem da Irrelevância da Estrutura de Capital de Modigliani e Miller (I958), do que propriamente o principal direcionador para a estrutura de capital (Octavia \& Brown, 2008). Como ainda existem controvérsias se, realmente, os acordos de capital regulatório podem ser considerados o principal determinante para explicar a estrutura de capital (Jucá, 2OII), outros elementos passam a ser incluídos nessas análises. Logo, as características da composição da estrutura de capital dos bancos passam a ser analisadas e explicadas com base em fatores relacionados a atributos das empresas bancárias, efeitos macroeconômicos e a própria regulação bancária (Romdhane, 20IO).

Nesse sentido, determinantes padrões da estrutura de capital têm sido apontados como os mais relevantes para definição do nível de alavancagem financeira dos bancos (Octavia \& Brown, 2008), como por exemplo, o tamanho do banco, a lucratividade bancária, as oportunidades de crescimento, os ativos tangíveis e o pagamento de dividendos (Jucá, 2OII). Outros aspectos que também podem influenciar na determinação da estrutura de capital dos bancos estão relacionados à estrutura de propriedade e controle gerencial, singularidade e reputação, benefício fiscal pelo uso do endividamento, riscos e custos de dificuldades financeiras (Salawu \& Awolowo, 2007), custo de capital, nível de depósitos (Romdhane, 20IO) e os programas de compensação de executivos (Jucá, 2OII).

Como os bancos apresentam maior exposição às flutuações do ciclo econômico em comparação às empresas não financeiras, determinados aspectos relacionados a indicadores macroeconômicos, como por exemplo, o crescimento do Produto Interno Bruto (PIB), a volatilidade do retorno de mercado e a inflação (Octavia \& Brown, 2008; Gropp \& Heider, 20Io), podem influenciar significativamente nas decisões de estrutura de capital dessas empresas. A presença da regulação bancária e os 
instrumentos de segurança disponibilizados por governos e órgãos privados relacionados a seguros de depósitos, o papel dos bancos centrais como reguladores e credores em determinadas situações e os requerimentos de capital regulatório, são outros fatores determinantes para a estrutura de capital dos bancos (Berger, Herring \& Szegö, I995; Gropp \& Heider, 20IO; Harding, Liang \& Ross, 2006; Kwan, 2009; Mishkin, 2000; Santos, 200I).

Pelo exposto, determinados aspectos característicos da atividade bancária podem interferir diretamente na estrutura de capital dos bancos. Em outras palavras, a regulação do setor bancário, os requerimentos de capital regulatório e fatores representativos de atributos específicos dos bancos e do próprio ambiente institucional e macroeconômico em que atuam, são alguns dos elementos que revelam as imperfeições existentes nos mercados que podem afetar a estrutura de capital dos bancos, permitindo assim intuir pela sua relevância para a maximização de valor (Aboura \& Lépinette, 20I5).

Admite-se ainda que a estrutura de capital dos bancos possa ser definida com base nas decisões de gerenciamento de riscos, dado ao fato do capital não ser usado como forma de financiamento, mas sim como buffers de capital contra aqueles ativos que estão expostos a riscos e que necessitam ser gerenciados (Peura \& Keppo, 2006). A maioria dos bancos tem optado por manter níveis de capital em reservas acima dos valores mínimos exigidos para o capital regulatório (Jokipii \& O Milne, 2008, 20II), por não ser possível a realização de ajustes instantâneos na recomposição do capital e tampouco a venda ou mudanças imediatas no portfólio de investimentos (Stolz \& Wedow, 2OII).

Logo, na determinação da estrutura de capital os bancos buscam maximizar o retorno do capital existente ao levar em conta o trade-off entre custo de ajustamento de capital (custos gerados pela obtenção de novos recursos para recompor o nível de capital), custo de manutenção de capital (custos associados à decisão de manter determinado capital que não será remunerado aos acionistas), custo de falência (custos decorrentes do não atendimento das exigências de capital regulatório ou custo da não devolução dos créditos emprestados a seus clientes) entre outros fatores que possam afetar sua estrutura de capital (Belém \& Gartner, 20I6). 


\section{Consideracões Finais}

Este ensaio teve por objetivo abordar os principais argumentos que sinalizam para a relevância da estrutura de capital para os bancos. Para isso, a pesquisa apoiou-se nas principais teorias sobre a estrutura de capital que estão previstas na Teoria de Finanças e em aspectos particulares da atividade bancária, com a intenção de identificar argumentos válidos que possam assegurar, ainda que com base em uma abordagem teórica, a relevância da estrutura de capital para essas empresas. Ao finalizar a construção deste ensaio, nota-se que o modo como os recursos financeiros são captados pelos bancos para serem negociados sob a forma de operações de empréstimos e de investimentos, pode afetar significativamente os seus resultados.

Maiores níveis de depósitos de clientes compondo a estrutura de capital dessas empresas proporcionam um maior volume de recursos disponíveis para a intermediação financeira, representando uma forma de captação oportuna e menos onerosa, principalmente pelo fato de ser obtida a taxas de juros reduzidas, geralmente abaixo da taxa livre de risco da economia, ou até mesmo isento de ônus como ocorre com os depósitos à vista, contribuindo para a maximização de valor nos bancos.

Por outro lado, dependendo da situação financeira dos bancos, maiores níveis de endividamento na estrutura de capital podem representar baixa capitalização, levando os depositantes a exigir juros mais elevados sobre seus depósitos em razão do aumento de propensão ao risco, elevando assim os custos associados à captação de recursos e impactando na maximização de valor. Aspectos como garantias e proteções oferecidas por órgãos privados e governamentais (seguros de depósitos e garantias implícitas de resgate) contribuem para mitigar os riscos no setor bancário e reduzir os custos de captação com os depositantes, criando estímulos para que os bancos mantenham elevados níveis de recursos de terceiros na estrutura de capital.

Grandes bancos, geralmente, criam expectativas de que possa haver socorro do governo em caso de dificuldades financeiras, dadas as implicações relacionadas ao risco sistêmico e a grande importância dessas instituições para as economias, alguns deles conhecidos como grande demais para quebrar (too big to fail). A elevada dependência 
de recursos do capital de terceiros na composição da estrutura de capital, sobretudo de depósitos de clientes, denota a grande capacidade dos bancos de alavancagem financeira dos resultados. Consequentemente, a participação do capital próprio na estrutura de capital acaba se tornando bastante reduzida, geralmente em níveis que sejam compatíveis com as expectativas de mercado e suficientes para atendimento das exigências de capital regulatório previstas nos Acordos de Basileia.

Determinadas particularidades da indústria financeira como os requerimentos de capital regulatório, a regulação governamental, a preferência por operar com recursos de terceiros na estrutura de capital, as garantias e proteções oferecidas por governos e órgãos privados e algumas imperfeições existentes nos mercados como os benefícios fiscais pelo uso de endividamento, riscos de insolvência e custos privados de falência, problemas de relação de agência e a assimetria de informações, são alguns aspectos que podem interferir diretamente sobre as decisões de estrutura de capital nos bancos.

A administração da estrutura de capital nessas empresas envolve decisões quanto à determinação da estrutura ótima de capital que precisam ser tomadas de maneira dinâmica. Considerando-se que os bancos atuam em ambientes de mercados reais e imperfeitos poder-se-ia então inferir sobre a relevância da estrutura de capital para essas empresas. Desse modo, teorias como a Static-Tradeoff Theory, a Pecking Order Theory e a Teoria de Agência parecem perfeitamente aplicáveis aos bancos, distanciando a realidade do ambiente em que atuam essas empresas da abordagem da Irrelevância da Estrutura de Capital proposta por Modigliani e Miller (I958).

Destaque-se, para este tipo de artigo, que na construção de um ensaio teórico, não é preciso o desenvolvimento de uma conclusão no sentido tradicional, pois cada parte desse tipo de análise trata-se de uma conclusão por si mesma (Meneghetti, 2OII). Nesse sentido, algumas inferências foram possíveis de ser construídas e exploradas ao longo deste ensaio, representando um esforço analítico, ainda que possa ser considerado incipiente num primeiro momento da análise, sobre os principais aspectos que sinalizam para a relevância da estrutura de capital para os bancos.

Por fim, ressalte-se ao leitor do artigo que este ensaio não se propõe a esgotar o assunto explorado, tampouco produzir conclusões definitivas acerca da relevância da 
estrutura de capital para os bancos. Logo, recomenda-se que as pesquisas futuras nesta área promovam um maior aprofundamento nos aspectos delineados ao longo deste texto, bem como em outras questões pertinentes, que encorajem a realização de novos ensaios-teóricos e/ou pesquisas empíricas que venham a abordar a estrutura de capital nas empresas do setor financeiro.

\section{Referèncias}

Aboura, S., \& Lépinette, E. (20I5). Do banks satisfy the Modigliani-Miller theorem? Economics Bulletin, v. 35, n. 2, p. 924-935.

Andrade, C. R. (2OI4). Basileia III: Uma análise das novas recomendações do Comitê de Supervisão Bancária da Basileia sobre o Setor Financeiro Brasileiro. Dissertação de Mestrado. Universidade Federal do Rio Grande do Sul (UFRGS). Porto Alegre. RS. Brasil.

Assaf Neto. (2015). Estrutura e Análise de Balanços: Um Enfoque EconômicoFinanceiro. $\Pi^{\mathrm{a}}$ ed., São Paulo: Atlas.

Assis, J. S. (2OI7). Análise do RAROC utilizando modelo DuPont dos bancos privados listados na BM\&FBOVESPA de 2010 a 2OI5. Dissertação de Mestrado. Pontifícia Universidade Católica de São Paulo. São Paulo. SP. Brasil.

Baker, M., \& Wurgler, J. (2002). Market Timing and Capital Structure. The Journal of Finance, v. 57, n. I, p. I-32.

Banco Central do Brasil [BACEN]. (2019a). Recomendações de Basileia. Banco Central do Brasil (BACEN).

Bank for International Settlements [BIS]. (I988). International Convergence of Capital Measurement and Capital Standards. Basel Committee on Banking Supervision.

Bank for International Settlements. (2006). International Convergence of Capital Measurement and Capital Standards: A Revised Framework Comprehensive Version. Basel Committee on Banking Supervision.

Bank for International Settlements. (2ОIO). Basel III: A global regulatory framework for more resilient banks and banking systems. Basel Committee on Banking Supervision.

Belém, V. C., \& Gartner, I. R. (2OI6). Análise Empírica dos Buffers de Capital dos Bancos Brasileiros no Período de 200I a 2OII. Revista de Contabilidade e Finanças USP. São Paulo, v. 27, n. 7O, p. II3-I24.

Berger, A. N., Herring, R. J., \& Szegö, G. P. (1995). The Role of Capital in Financial Institutions. Wharton Financial Institutions Center. Working Paper 95-OI, p. I55 .

Berger, A. N., \& Patti, E. B. (2005). Capital Structure and Firm Performance: A New Approach to Testing Agency Theory and an Application to the Banking Industry. Journal of Banking and Finance. 
Boava, D. L. T., Macedo, F. M. F., \& Sette, R. S. (2OI2). Contribuições do Ensaio Teórico para os Estudos Organizacionais. In: VII Encontro de Estudos Organizacionais da ANPAD, EnEO 20I2. ANPAD. Curitiba.

Brealey, R. A., Myers, S. C., \& Allen, F. (2013). Princípios de Finanças Corporativas. Tradução: Paschoa, C. R.; Revisão Técnica: Douat, J. C. Io. ed. Porto Alegre: AMGH Editora.

Brewer III, E., Kaufman, G. G., \& Wall, L. D. (2008). Bank capital ratios across countries: Why do they vary? Federal Reserve Bank of Atlanta. Working Paper, n. 27 , p. I-40.

Caağlayan, E., \& Şak, N. (2OIO). The Determinants of Capital Structure: Evidence from the Turkish Banks. Journal of Money, Investment and Banking, n. I5, p. 57-65.

Correa, C. A., Basso, L. F. C., \& Nakamura, W. T. (20I3). A Estrutura de Capital das Maiores Empresas Brasileiras: Análise Empírica das Teorias de Pecking Order e Trade-Off, usando Panel Data. Revista de Administração Mackenzie. v. I4, n. 4, p. Iо6-г33.

Diamond, D. W., \& Rajan, R. G. (200I). Liquidity Risk, Liquidity Creation, and Financial Fragility: A Theory of Banking. Journal of Political Economy, v. Io9, n. 2, p. $287-327$.

Durand, D. (1952). Costs of Debt and Equity Funds for Business: Trends and Problems of Measurement, In: CONFERENCE ON RESEARCH IN BUSINESS FINANCE, I952, Universities-National Bureau, p. 2I5-262.

Durand, D. (1959). The Cost of Capital, Corporation Finance, and the Theory of Investment: Comment. The American Economic Review, v. 49, n. 4, p. 639-655.

Elizalde, A., \& Repullo, R. (2007). Economic and regulatory capital in banking: What is the difference? International Journal of Central Banking, v. 3(3), p. 87-II7.

Famá, R., Barros, L. A. B. C., \& Silveira, A. D. M. (200I). A Estrutura de Capital é Relevante? Novas Evidências a partir de dados Norte-Americanos e LatinoAmericanos. Caderno de Pesquisas em Administração, São Paulo, v. 8, n. 2, p. 7I84 .

Flannery, M. J., \& Rangan, K. (2006). Partial adjustment toward target capital structures. Journal of Financial Economics. v. 79, p. 469-5o6.

Frank, M. Z., \& Goyal, V. K. (2009). Capital structure decisions: which factors are reliably important? Financial Management. v. 38, n. I, p. I-37.

Goes, K. C., Sheng, H. H., \& Schiozer, R. F. (20I6). Contingentes Conversíveis e seus Impactos na Otimização da Estrutura de Capital de Bancos Brasileiros sob Basileia III. Revista de Contabilidade e Finanças USP. São Paulo, v. 27, n. 7o, p. 80-97.

Gonçalves, R. S., Tavares, A. L., Ximenes, P. M., \& Silva, R. M. P. (20I2). Comportamento dos Dez Maiores Bancos Brasileiros Durante a Crise do Subprime: Uma Análise por Meio de Indicadores Contábeis. Revista de Educação e Pesquisa em Contabilidade. Brasília, v. 6, n. 2, p. I70-I86.

Gropp, R., \& Heider, F. (20IO). The Determinants of Bank Capital Structure. Review of Finance, v. I4(4), p. 587-622. 
Harding, J., Liang, X., \& Ross, S. (2006). The Optimal Capital Structure of Banks Under Deposit Insurance and Capital Requirements. Working Papers Series, Social Science Research Network, p. I-4I.

Jensen, M. C. (I986). Agency costs of free cash flow, corporate finance and takeovers. American Economic Review, v. 76 , n. 2, p. 323-329.

Jensen, M. C., \& Meckling, W. H. (1976). Theory of the Firm: Managerial Behavior, Agency Costs and Ownership Structure. Journal of Financial Economics, v. 3, n. 4, p. 305-36o.

Jokipii, T., \& Milne, A. (2008). The cyclical behavior of European bank capital buffers. Journal of Banking and Finance, v. $3^{2}(8)$, p. I44O-I 45I.

Jokipii, T., \& Milne, A. (2OII). Bank capital buffer and risk adjustment decisions. Journal of Financial Stability, v. 7(3), p. I65-178.

Jucá, M. N. (2OII). Determinantes da Estrutura de Capital de Bancos Brasileiros e Norte-Americanos. Tese de Doutorado. Universidade de São Paulo. São Paulo. SP. Brasil.

Kakinami, K. (2007). Evolução do grau de alavancagem dos bancos comerciais brasileiros e a regulação: Uma visão comparativa do período de I950 a 2005 . Dissertação de Mestrado. Universidade de São Paulo. São Paulo. SP. Brasil.

Kleff, V., \& Weber, M. (2008). How do banks determine capital? Empirical evidence from Germany. German Economic Review, v. 9, n. 3, p. 354-372.

Kwan, S. (2009). Capital Structure in Banking. Federal Reserve Bank of San Francisco, Economic Letter, n. 37, p. I-5.

Machado, L. K. G., Prado, J. W., Vieira, K. C., Antonialli, L. M., \& Santos, A. C. (2OI5) A Relevância da Estrutura de Capital no Desempenho das Firmas: Uma Análise Multivariada das Empresas Brasileiras de Capital Aberto. Revista de Educação e Pesquisa em Contabilidade, Brasília, v. 9, n. 4, p. 397-4I4.

Maffili, D. W., Bressan, A. A., \& Souza, A. A. (2007). Estudo da Rentabilidade dos Bancos Brasileiros de Varejo no período de 1999 a 2005. Contabilidade Vista e Revista, v. I8, n. 2, p. II7-I38.

Mantovani, M. H. C., \& Santos, J. O. (20I5). Análise da Relação entre Alavancagem e Rentabilidade dos Bancos Brasileiros Listados na Bolsa de Valores de São Paulo no Período de 2OOI a 2OIO. REGE Revista de Gestão, São Paulo, v. 22, n. 4, p. 509-524.

Martelanc, R. (20IO). Contribuição Metodológica para Elaboração de Artigos em Finanças. Revista de Finanças Aplicadas, v.I, p. I-24.

Mendonça, D. J., Souza, J. A., Benedicto, G. C., \& Silva, S. N. A. (20I6). Relação entre Eficiência Econômico-Financeira e Lucratividade em Instituições Bancárias Brasileiras. In: XIX Seminários em Administração - SemeAd 20ı6. USP. São Paulo.

Meneghetti, F. K. (2OII). O que é um Ensaio-Teórico. Revista de Administração Contemporânea, v. I5, n. 2, p. 320-332.

Miller, M. H. (I977). Debt and taxes. The Journal of Finance, v. 32, n. 2, p. 26I-275. 
Miller, M. H. (I995). Do the M\&M propositions apply to banks? Journal of Banking and Finance, n. 19, p. $483-489$.

Mishkin, F. S. (2000). The economics of money, banking and financial markets. Addison Wesley, New York.

Modigliani, F., \& Miller, M. H. (1958). The Cost of Capital, Corporation Finance and the Theory of Investment. The American Economic Review, v. 48, n. 3, p. 26I-297.

Modigliani, F., \& Miller, M. H. (I963). Corporate Income Taxes and the Cost of Capital: A Correction. The American Economic Review, v. 53, n. 3, p. 433-443.

Myers, S. C. (i977). Determinants of corporate borrowing. Journal of Financial Economics, v. 5, n. 2, p. I47-I75.

Myers, S. C. (I984). The Capital Structure Puzzle. The Journal of Finance, v. 39, n. 3, p. 574-592.

Myers, S. C. (200I). Capital Structure. The Journal of Economic Perspectives, v. I5, n. 2, p. 8I-IO2.

Myers, S. C., \& Majluf, N. S. (I984). Corporate Financing and Investment Decisions when Firms Have Information that Investors do not Have. Journal of Financial Economics, v. I3, n. 2, p. I87-22I.

Nisiyama, E. K., \& Nakamura, W. T. (2015). Pesquisas Internacionais Recentes em Estrutura de Capital. Revista de Administração de Roraima, Boa Vista, v. 5, n. I, p. IO5-I23.

Octavia, M., \& Brown, R. (2008). Determinants of bank capital structure in developing countries: regulatory capital requirement versus the standard determinants of capital structure. Working Paper. Social Science Research Network.

Orgler, Y. E., \& Taggart Jr, R. A. (1983). Implications of Corporate Capital Structure Theory for Banking Institutions. Journal of Money, Credit and Banking, v. I5, n. 2, p. 2I2-22I.

Paula, L. F. R. (I999). Dinâmica da firma bancária: Uma abordagem não-convencional. Revista Bancária de Economia. v. 53, n. 3, p. 323-356.

Paula, L. F. R., Alves Júnior, A., \& Marques, M. B. L. (200I). Ajuste patrimonial e padrão de rentabilidade dos bancos privados no Brasil durante o Plano Real (I994/1998). Estudos Econômicos, São Paulo, v. 3I, n. 2.

Peura, S., \& Keppo, J. (2006). Optimal bank capital with costly recapitalization. The Journal of Business. v. 79(4), p. 2I63-22OI.

Pinheiro, F. A. P., Savóia, J, R. F., \& Securato, J. R. (20I5). Basileia III: Impacto para os Bancos no Brasil. Revista Contabilidade e Finanças, São Paulo, v. 26, n. 69, p. 345-36r.

Prescott, E. S. (200I). Regulating Bank Capital Structure to Control Risk. Federal Reserve Bank of Richmond Economic Quarterly, v. 87, n. 3, p. 35-52.

Rime, B. (200I). Capital requirements and bank behavior: Empirical evidence for Switzerland. Journal of Banking and Finance, v. 25(4), p. 789-805. 
Romdhane, M. (2OIO). The Determinants of Banks' Capital Ratio in Developing Countries: Empirical Evidence from Tunisia. Social Science Research Network (SSRN).

Ross, S. A. (1977). The Determination of Financial Structure: The Incentive-Signalling Approach. The Bell Journal of Economics, v. 8, n. I, p. 23-40.

Salawu, R. O., \& Awolowo, O. (2007). The determinants of the capital structure of financial firms in Nigeria: The financial manager's perspectives. Global Journal of Business Research, v. I, n. I, p. 6o-69.

Santos, J. (200I). Bank Capital Regulation in Contemporary Banking Theory: A Review of the Literature. Financial Markets, Institutions \& Instruments, v. IO, n. 2, p. 4I-84.

Saunders, A. (2000). Administração de Instituições Financeiras: Tradução Antonio Zoratto Sanvicente. São Paulo: Atlas.

Silva, V. P., Rodrigues, D. R., Pereira, V. S., Rezende, C. F., \& Tizziotti, C. P. P. (20I6). Uma análise da estrutura de capital das empresas brasileiras internacionalizadas. In: XIX Seminários em Administração - SemeAd 2oI6. USP. São Paulo.

Souza, F. H. R. (2003). Estruturas de Capitais e de Ativos de Instituições Financeiras Brasileiras: Influências das Regulamentações no Contexto do Acordo da Basileia. Dissertação de Mestrado. Pontifícia Universidade Católica de Minas Gerais. Belo Horizonte. MG. Brasil.

Stolz, S., \& Wedow, M. (2OII). Banks' regulatory capital buffer and the business cycle: Evidence for Germany. Journal of Financial Stability, v. 7(2), p. 98-IIO.

Vallascas, F., \& Hagendorff, J. (20I3). The risk sensitivity of capital requirements: evidence from an international sample of large banks. Review of Finance, v. I7 (6), p. 1947-I988.

Vieira, C. A. M. (20I6). Determinantes da Lucratividade Bancária: Evidências do Sistema Financeiro Brasileiro. In: XIX Seminários em Administração - SemeAd 20ı6. USP. São Paulo.

Wall, L. D., \& Peterson, P. P. (r998). The Choice of Capital Instruments. Federal Reserve Bank of Atlanta, Economic Review, p. 4-I7. 